\title{
Representações sobre a Aids na velhice por coordenadoras de grupos da terceira idade ${ }^{1}$
}

\author{
Ana Alayde de Werba Saldanba - Universidade Federal da Paraíba ${ }^{2}$ \\ Shenia Maria Felicio Felix - Universidade Federal da Paraíba \\ Ludgleydson Fernandes de Araújo - Universidade Federal da Piauí
}

\begin{abstract}
Resumo
O presente trabalho buscou apreender as representações das coordenadoras dos grupos de convivência de idosos sobre Aids na velhice. Participaram da pesquisa 20 coordenadoras do Programa de Atenção ao Idoso da Prefeitura Municipal de João Pessoa-PB, com idade variando de 38 a 72 anos. Para a coleta dos dados foi utilizado um questionário sociodemográfico e a técnica de Associação Livre de Palavra, a partir de três estímulos indutores: Aids na terceira idade, prevenção e vulnerabilidade. Emergiram as seguintes representações: as coordenadoras mais jovens associam a Aids à necessidade de cuidado, e a prevenção, ao uso de camisinha. A vulnerabilidade é associada a um fenômeno relativo a todos. Para as de maior idade, as representações estão associadas a sofrimento e a grupo de risco. O desenvolvimento de práticas educativas nos grupos constitui espaços de transformação para intervenções preventivas quanto ao HIV/Aids.

Palavras-chave: Aids; Prevenção; Grupos de convivência de idosos.
\end{abstract}

\section{Representations about Aids in old age by coordinators of groups the third age}

\begin{abstract}
This study aimed seize the representations of the coordinating groups of coexistence of Aids on older persons in old age. Participants of the survey of 20 coordinating of the Attention Program for the Elderly Municipality of Joao Pessoa-PB, with ages ranging from 38 to 72 years. For data collection was used a questionnaire socio-demographic and technical Association Freedom of Word, from three stimuli inducers: Aids in the elderly, prevention and vulnerability. Emerged the following offices: the coordinating younger associate to the need for Aids care and prevention, the use of condoms. The vulnerability is related to a phenomenon for all. For those of greater age, the representations are associated with suffering and group risk. The development of educational practices in groups constitutes spaces processing for preventive interventions front of the HIV/Aids.

Keywords: Aids; Prevention; Groups of living together of aged.
\end{abstract}

\section{Introdução}

\section{A Aids e suas dinâmicas}

A Aids é um dos graves problemas da saúde coletiva na atualidade. Desde seu surgimento, nos fins dos anos 70, ela vem se apresentando como uma doença dinâmica, possuindo uma série de características que se diversificam ao longo da história, impulsionando a busca por sua compreensão. Inicialmente, ficou conhecida como a doença configurada pela morte, pelo contágio, pelo sexo, graças à apresentação bastante reforçada pela mídia. (Saldanha, Figueiredo \& Coutinho, 2005). Rapidamente surgem os "grupos de risco" (homossexuais, prostitutas e usuários de drogas injetáveis), que ficam conhecidos como o lócus da doença, e seus integrantes, como os seus disseminadores e desviantes das normas sociais relacionadas ao prazer, ao uso do sexo e à utilização de drogas. Muitos discursos foram elaborados para tratar a doença do "outro", do "promíscuo", do "morto-vivo", causando estigmatizações e demarcando o preconceito àqueles que lidavam com a doença (Gadelha, 2001).

A disseminação da doença começa a configurar-se de forma diferenciada da inicial e grupos, antes não identificados como passíveis de contaminação pelo HIV, passam a integrar o cenário epidemiológico da doença. A população em geral começa a ser também contaminada e junto a isso, na busca de combater a discriminação e os preconceitos causados pela denominação de "grupo de risco", surge o conceito de vulnerabilidade, que amplia a visão acerca das formas de contaminação pelo vírus HIV, atentando-se agora para o fato de que a possibilidade de contrair o vírus vai muito além da esfera individual, de apenas se ter ou não um comportamento de risco (Brasil, 2000; Saldanha, Araújo \& Felix, 2006). O conceito de

\footnotetext{
1 Apoio institucional do CNPq.

${ }^{2}$ Endereço para correspondência:

Av. Gov. Argemiro de Figueiredo, 505 - apto 101C - Bessa - 58037-030 - João Pessoa-PB

Tel: (83) 3246-8724

E-mail: ana.alayde.saldanha@pesquisador.cnpq.br
} 
vulnerabilidade considera a possibilidade de exposição das pessoas ao adoecimento de forma coletiva sem particularizar o individual, ajudando a compreender melhor como determinantes sociais influenciam na disseminação da doença (Saldanha e cols., 2005).

No Brasil e no mundo, com toda a complexidade e dinamismo da epidemia da Aids/HIV, o debate sobre a relação entre vulnerabilidade à infecção para o HIV e iniqüidades sociais se apresenta de forma urgente. Buscando um afastamento cada vez maior das generalizações dos achados, tenta-se, mediante um debate mais amplo, trazer à tona singularidades dos diversos contextos sociopolíticos e culturais existentes em nossa sociedade (Marques, 2003). Em um país como o Brasil, com tantas desigualdades sociais, com uma concentração de renda exorbitante nas mãos de poucos, com um acesso restrito aos bens de consumo, materiais e simbólicos, por parte de uma população mais carente - que é maioria no país-, o risco de cometer equívocos, ao compreender de forma generalizada a vulnerabilidade à infecção para o HIV, aumenta consideravelmente.

Ao longo do percurso histórico da Aids, fenômenos como a pauperização e a interiorização da doença foram fundamentais na sua redefinição. As barreiras enfrentadas pelos brasileiros das camadas sociais mais desfavoráveis, que minimizam a eficácia dos processos preventivos nesses seguimentos, e o aumento no número de casos em municípios menores tornaram-se focos relevantes de atenção no estudo da epidemia; assim como também ocorreu com o fenômeno da feminização da Aids (Lopes, 2005).

Como houve um grande processo de luta pela estabilização do número de casos e pela prevenção do contágio pelo vírus HIV entre os homossexuais, ocorreu uma mudança no panorama da epidemia: muitos casos de pessoas infectadas começaram a surgir por transmissão heterossexual, que é considerada por Bastos (2001) como o "motor" da dinâmica da epidemia, fazendo também com que o número de casos de mulheres infectadas aumentasse substancialmente. A autora ainda afirma que a epidemia atingiu de forma muito abrangente a realidade brasileira, onde a principal via de transmissão se confunde com os hábitos sexuais da população geral, dificultando até mesmo uma especificidade na definição das regiões sob um maior risco, bem como reivindicando uma política de prevenção mais abrangente.

Tendo em vista que a transmissão do vírus aumentou muito através das relações heterossexuais, conseqüentemente também aumentou o número de mulheres que passaram a ser infectadas pelo vírus HIV, principalmente por seus companheiros, usuários de drogas injetáveis (UDI's), que utilizam esporadicamente o preservativo. Vale ressaltar que, no caso do processo de feminização da epidemia, há uma desigualdade de gênero aparente, no que diz respeito às estratégias de prevenção e tratamento das mulheres infectadas, provocando assim uma maior vulnerabilidade à infecção pelo HIV. Somado a isso, temos todo um percurso histórico de desigualdades sociais, políticas e culturais vividos pelas mulheres que corroboram essa vulnerabilidade (Brasil, 2000).

Do ponto de vista social, as relações ocorrem de forma desigual, em que o acesso aos bens materiais e simbólicos favorece os homens, até mesmo no que diz respeito a métodos de prevenção. $\mathrm{O}$ controle exercido pelas mulheres é pequeno, o uso do preservativo feminino é caro, privilegiando as camadas mais ricas, fazendo com que as mulheres pertencentes à classe social menos favorecida economicamente fiquem dependentes de acordos entre seus parceiros. Além disso, a carga sociomoral que as mulheres carregam ainda hoje, no que diz respeito aos seus comportamentos sexuais, causa uma grande disparidade no tratamento das pessoas infectadas, criando, muitas vezes, estigmatizações que só dificultam o processo de prevenção da infecção. As desigualdades referentes ao tratamento quanto às diferenças de gênero se exarcebam ainda mais naquelas mulheres de camadas mais pobres, pois, além dos fatores já citados, a estrutura social aparece como um fator determinante na constituição e perpetuação de políticas de prevenção para essas classes. (Saldanha, 2003).

\section{HIV/Aids e velhice}

Desde o seu surgimento, a Aids vem trazendo ao debate público assuntos que anteriormente eram discutidos apenas no âmbito do privado ou eram negligenciados por possuírem uma carga sociomoral que lhes proibia serem debatidos. O impacto da epidemia da Aids trouxe à discussão dados quantitativos sobre comportamento sexual (Parker \& Barbosa, 1996). A diversidade sexual sempre esteve presente na sociedade humana, mas a forma de tratar esse assunto sempre foi proibida; o conservadorismo advindo da igreja católica e das práticas cristãs dificultou tratar os comportamentos sexuais como constituintes do cotidiano, relegando apenas ao casamento o seu único lugar possível, ou então às práticas confessionárias, que redimiam aqueles com comportamentos sexuais "desviantes" (Lima, 2006).

Os dados epidemiológicos da Aids demonstram que a categoria de exposição ainda em ascensão é o contágio do vírus pela via sexual, uma via de contágio que continua crescendo nas variadas faixas etárias e em ambos os sexos. Com sua dinamicidade, a epidemia da Aids atingiu ao longo dos anos, de forma indiscriminada, indivíduos, independentes de cor, sexo, idade e classe social. A partir desse pressuposto, começou-se a atentar para o crescimento do número de pessoas com Aids na 
faixa etária de 50 anos ou mais. As estatísticas nacionais apontam um total de 31.356 casos de Aids em maiores de 50 no Brasil, dos quais, 8.101 em pessoas com idade de 60 anos e mais (Brasil, 2005).

Em pesquisa realizada por Butin (2002), observou-se que a soropositividade nos idosos expõe o que estaria escondido, dificultando o discurso acerca do exercício da sexualidade e da prevenção, principalmente pela crença de que, com a chegada da velhice, os indivíduos tornam-se assexuados e, portanto, não existiria risco de infecção pelo HIV.

Diante de confirmação das atividades sexuais nos idosos, torna-se imprescindível que as políticas de prevenção às DST/Aids contemplem esse grupo etário, considerando suas particularidades, para que os objetivos sejam alcançados com eficiência. Todo o desenvolvimento da indústria farmacêutica, medicamentos, injeções e até próteses foram criados para resolver problemas de disfunção erétil nos homens. Aliadas a isso, as terapias de reposição hormonal, também para mulheres, visam oferecer uma vida sexual mais cheia de estímulos, com muito prazer e liberdade pelo maior período de vida possível. Porém, em propagandas desses produtos não se tem uma campanha que alerte aos idosos sobre os riscos de contrair Aids pela via sexual (Cruz, 2005).

Torna-se relevante compreender que, assim como na epidemia da Aids, o fenômeno da feminização da epidemia em idosos está presente. Fala-se de uma feminização da velhice a partir de dados que mostram que a população de mulheres velhas é superior à dos homens, impulsionando assim a criação de respostas a essa demanda específica, especialmente na área de saúde e de cuidados. Assim, é fundamental, portanto, não se perder de vista o grupo etário acima dos 50 anos como vulnerável também ao HIV, e, em especial, as mulheres mais velhas (Cavalcante, 2004).

Envelhecer sendo soropositivo para o HIV, ou contrair $O$ vírus na velhice representam um desafio duplicado para quem enfrenta essa situação (Saldanha, Araújo \& Felix, 2006). Além de toda a carga sociomoral que carrega o soropositivo de qualquer faixa etária, na velhice algumas construções sociais contribuem para $O$ aumento das dificuldades enfrentadas pelo idoso soropositivo. O receio da dupla rejeição social leva muitos idosos a buscarem mecanismos de aceitação social, o que pode ser observado na pesquisa de Butin (2002), quando, ao serem indagados pela forma de contaminação, os idosos recorreram às formas socialmente aceitas, como a transfusão de sangue, mas ao longo das entrevistas deixam entrever comportamentos sexuais vulneráveis.

Faz-se necessário que muitos estigmas e estereótipos atribuídos à velhice e à Aids sejam combatidos, que os idosos sejam vistos como integrantes da sociedade, como atores sociais importantes e que, diante dsso, eles sejam favorecidos nas políticas públicas sociais. Muitos idosos já vêm se reunindo, alguns não com o intuito de lutar por conquistas, mas pela necessidade de estar juntos, em momentos de lazer, a fim de que não se sintam isolados nem socialmente rejeitados. Tal fato aponta para uma possibilidade de esses grupos já integrados também se unirem a outros e lutarem por melhorias na qualidade de vida. Esse espaço passa a ser de muita importância para práticas educativas junto aos idosos, sendo extremamente relevante para a promoção e prevenção às DST's/Aids.

\section{Os grupos de convivência}

Com o crescimento da população idosa no Brasil e no mundo, uma série de iniciativas, públicas e privadas, precisou ser implementada na tentativa de atender o contingente populacional de mais idade. De acordo com Cabral e Oliveira (2003), uma das mais importantes iniciativas foi a criação dos grupos de convivência para idosos. Os primeiros grupos aconteceram em países do continente europeu, expandindo-se rapidamente para outros países. "Essa foi, possivelmente, a primeira concepção mais aberta de se atender a população longeva, criando-lhe oportunidades de retorno e à participação comunitária" (p. 59).

Os grupos de convivência de idosos permitem aos seus integrantes uma inserção social, mediante espaços para o lazer, sociabilidade, cultura e para a construção de uma consciência de cidadania, fazendo com que os idosos adquiram um sentimento de pertença e não de exclusão. É nesse espaço que eles podem colocar suas ansiedades e encontrar respostas junto ao grupo para seus questionamentos sociais e problemas familiares, além de que tais grupos atuam também como suporte psicológico (Costa \& Campos, 2003). Através da reflexão, do debate e da aprendizagem coletiva, as ações de intervenção na velhice tornam-se efetivas. Vistos como agentes ativos, os estereótipos negativos de incapacidade e inutilidade relacionados aos idosos tendem a se desfazer (Araújo, Coutinho \& Santos, 2006).

Com toda a relevância dos dados da Aids em idosos, os grupos de convivência tornam-se espaços privilegiados para o desenvolvimento de programas preventivos. Segundo estudos de Figueiredo (2004), uma vez que as informações relevantes não surtem o efeito desejado, em razão da representação social da Aids junto à comunidade, os líderes e agentes comunitários poderiam se constituir elos importantes entre a população e os profissionais que atuam na comunidade, considerando a possibilidade de estes apresentarem representações mais próximas da realidade e adequadas às formas de atuação. Tais representações apresentam uma generalidade que aproxima os líderes de seus pares na comunidade em geral, 
o que reforça a necessidade de, ao tratar-se de grupos de terceira idade, serem estendidos os programas de formação e orientação aos coordenadores que neles atuam.

Partindo da premissa de que os grupos de convivência da terceira idade propiciam formas de empoderamento de cidadania para o cotidiano de seus participantes, através da reflexão do seu entorno sociocultural, além de suscitar mecanismos individuais e coletivos para ações positivas na velhice (Araújo, Coutinho \& Carvalho 2005), e considerando a influência que os líderes de grupos sociais podem exercer em seus integrantes, o presente estudo tem como objetivo identificar as representações da Aids por coordenadoras de grupos de convivência de idosos, buscando conteúdos relevantes que possam ser incorporados ou modificados em programas de informação e prevenção à doença.

\section{Método}

\section{Participantes}

Participaram 20 coordenadoras dos grupos de idosos que estão inseridos no Programa de Atenção ao Idoso, da Secretaria de Desenvolvimento Social (SEDES) da Prefeitura Municipal de João Pessoa. Todas as participantes eram do sexo feminino, com idade variando de 38 a 72 anos, com nível de instrução superior e tempo de trabalho no grupo de 4 meses a 26 anos. As participantes dispunham do livre arbítrio para participar ou não da pesquisa.

\section{Instrumentos}

Para a coleta de dados foi utilizado um questionário com os dados sociodemográficos, visando à caracterização da amostra e à técnica de Associação Livre de Palavras, que consiste em um tipo de investigação aberta que se estrutura na evocação de respostas dadas com base em um ou mais estímulos indutores (Coutinho, 2001). Essa técnica possibilita o acesso a conteúdos latentes que, no momento do estímulo, emergem, permitindo assim sua apreensão. Neste estudo os estímulos indutores foram três: Aids na terceira idade, prevenção e vulnerabilidade.

\section{Procedimentos}

Inicialmente, o projeto foi enviado ao Comitê de Ética em Pesquisa com Seres Humanos do CCS (Centro de Ciências da Saúde) da UFPB, com o intuito de averiguar os parâmetros éticos, tendo como base a Resolução $n^{\circ}$ 196/96. Tendo recebido parecer de aprovação para realização da pesquisa, solicitou-se a autorização das coordenações dos grupos de convivência de idosos inseridos nos programas de atenção aos idosos do governo do estado e da Prefeitura Municipal de João Pessoa.

Foi agendado horário disponível e local específico para o encontro entre cada coordenadora e a pesquisadora, a fim de serem aplicadas as técnicas e colhida a assinatura do termo de consentimento livre e esclarecido. As entrevistas foram realizadas pela pesquisadora, no local de realização dos grupos. Ocorreu um encontro com cada participante, com tempo de duração variando entre uma e duas horas. As entrevistas foram gravadas em fita cassete, com a devida autorização escrita das entrevistadas e, em seguida, transcritas na íntegra para possibilitar a análise dos dados.

\section{Análise dos dados}

Os dados sociodemográficos foram analisados através de estatística descritiva, com a utilização de medidas de posição (média, mediana) e de variabilidade (desvio padrão, amplitude). Os conteúdos apreendidos por meio da técnica de Associação Livre de Palavras foram processados pelo software Tri-deux-Mots (Cibois, 1998) e analisados por meio da Análise Fatorial de Correspondência (AFC), que permite a visualização das variáveis fixas e de opiniões no campo representacional.

\section{Resultados e discussão}

Serão apresentados a priori os resultados coletados por meio do questionário sociodemográfico em que as coordenadoras dissertaram sobre as atividades realizadas nos seus grupos e responderam a uma escala acerca de suas crenças em relação ao HIV/Aids na velhice. Em seguida serão apresentados os dados coletados na Associação Livre de Palavras (ALP), que permitiu que emergissem as concepções das coordenadoras dos grupos de convivência diante dos estímulos indutores: Aids na velhice, prevenção e vulnerabilidade.

Na Figura 1 podem ser visualizados os dados coletados pelo questionário sociodemográfico sobre aquilo em que acreditam as coordenadoras acerca da Aids na velhice. Ao assinalarem as afirmativas na coluna 1 , elas respondiam que discordavam fortemente da afirmativa; ao assinalarem na 2 , significava que apenas discordavam; ao assinalarem na 3 , que estavam em dúvida ou não tinham opinião a respeito; ao assinalarem na 4, que concordavam e na 5 , que concordavam fortemente com a afirmativa. 
Tabela 1 - Crenças das coordenadoras acerca da Aids na terceira idade

\begin{tabular}{|c|c|c|c|c|c|}
\hline Crenças & 1 & 2 & 3 & 4 & 5 \\
\hline Observo relutância nos idosos em falar sobre a Aids. & $26,3 \%$ & $36,8 \%$ & $5,3 \%$ & $15,8 \%$ & $15,8 \%$ \\
\hline $\begin{array}{l}\text { Os idosos acreditam que não têm o risco de se contaminar } \\
\text { com o HIV. }\end{array}$ & $31,6 \%$ & $21,1 \%$ & $21,1 \%$ & $15,8 \%$ & $10,5 \%$ \\
\hline Acredito que pessoas idosas não têm chance de pegar Aids. & $78,9 \%$ & $10,5 \%$ & - & - & $10,5 \%$ \\
\hline Não é importante falar com os idosos sobre Aids. & $78,9 \%$ & $10,5 \%$ & - & - & $10,5 \%$ \\
\hline $\begin{array}{l}\text { Tratar as questões da Aids em pacientes da terceira idade é } \\
\text { difícil. }\end{array}$ & $31,6 \%$ & $31,6 \%$ & $5,3 \%$ & $26,3 \%$ & $5,3 \%$ \\
\hline $\begin{array}{l}\text { Não me sinto bem em discutir sobre a Aids com pessoas da } \\
\text { terceira idade. }\end{array}$ & $57,9 \%$ & $31,6 \%$ & $5,3 \%$ & - & $5,3 \%$ \\
\hline
\end{tabular}

Pode-se constatar que as coordenadoras discordam, em sua maioria $(36,8 \%)$, de que exista relutância dos idosos(as) em falar sobre Aids; 31,6\% acreditam que os idosos(as) compreendem o risco de se contaminar com o HIV. As coordenadoras também acreditam na possibilidade de os idosos(as) contraírem o HIV/Aids, considerando também ser importante falar com eles acerca da doença; ambas as afirmativas tiveram uma porcentagem de 78,9\%. Em contrapartida, 31,6\% das coordenadoras consideram ser difícil tratar as questões de Aids na velhice e 57,9\% dizem sentir-se à vontade para tratar sobre essas questões com as pessoas na terceira idade.

Os resultados coletados por meio dos dados sociodemográficos apresentam o modo como, aos poucos, a temática da Aids vai sendo apreendida pelas coordenadoras, que buscam trazê-la para sua realidade. Partindo do particular para o geral, elas tentam dominar o assunto. Embora tenham afirmado majoritariamente não observar relutância dos idosos em falar sobre Aids e acreditar que eles tenham consciência de que podem contrair a doença, as coordenadoras divergem no que diz respeito à abordagem desse assunto com os idosos(as), pois, mesmo compreendendo a importância de falar com eles, 10,5\% discordam fortemente dessas afirmações, e, além disso, 31,6\% dos coordenadores afirmaram ser difícil tratar de questões referentes à Aids com pessoas idosas.

A compreensão da velhice como uma etapa da vida em que a sexualidade é tratada como algo distante da realidade do idoso está ainda impregnada no discurso das coordenadoras, mesmo que de forma implícita. Diante disso, este estudo vem reafirmar a necessidade de intervenções preventivas em saúde junto às coordenadoras, para que estas compreendam a especificidade das relações estabelecidas na velhice. A inserção de temáticas relativas à sexualidade do idoso e suas implicações no âmbito dos grupos de convivência possibilitam um novo olhar quanto à velhice, marcado pelo diálogo e pela discussão das situações, e não mais um olhar de exclusão, de distanciamento do que realmente continua acontecendo no dia-a-dia dos idosos.

Em estudo realizado por Borges (2006) acerca das representações de idosos(as) em grupos de convivência dos quais participam, e a repercussão destes sobre sua qualidade de vida, pode-se constatar como os grupos podem promover aquisição de novos conhecimentos e disponibilizar uma rede de apoio social ante as dificuldades que porventura possam surgir aos idosos. Constatou-se ainda que as vivências nos espaços dos grupos são fundamentais para a prevenção ao $\mathrm{HIV} /$ Aids e para a exploração do conhecimento dos idosos com relação ao tema saúde/doença e à educação para a saúde.

Diante do exposto, Reis e Fradique (2003), com o intuito de compreender melhor a forma como os adultos, em diferentes fases (jovem adulto, meiaidade e idosos), conceituam os processos de saúde e doença, concluíram haver diferenças no conteúdo das significações nos diferentes subgrupos etários. Especificamente no subgrupo dos idosos $(>$ de 65 anos), observou-se que, ao serem questionados sobre as causas das doenças e sobre a prevenção destas, eles se referiram à impossibilidade de prevenir algumas doenças hereditárias e à falta de cuidado pessoal como fontes causadoras de doenças.

Os resultados do questionário sociodemográfico são corroborados pelos dados a seguir, coletados por meio do teste de Associação Livre de Palavras. Este, enquanto instrumento de apreensão de significados do conhecimento prático, possibilitou, juntamente com as variáveis fixas - profissão, idade e tempo de trabalho no grupo -, a emersão de campos semânticos sobre a Aids no contexto da terceira idade, conforme pode ser observado no plano fatorial, através dos dois fatores nele contemplados (F1 e F2). 


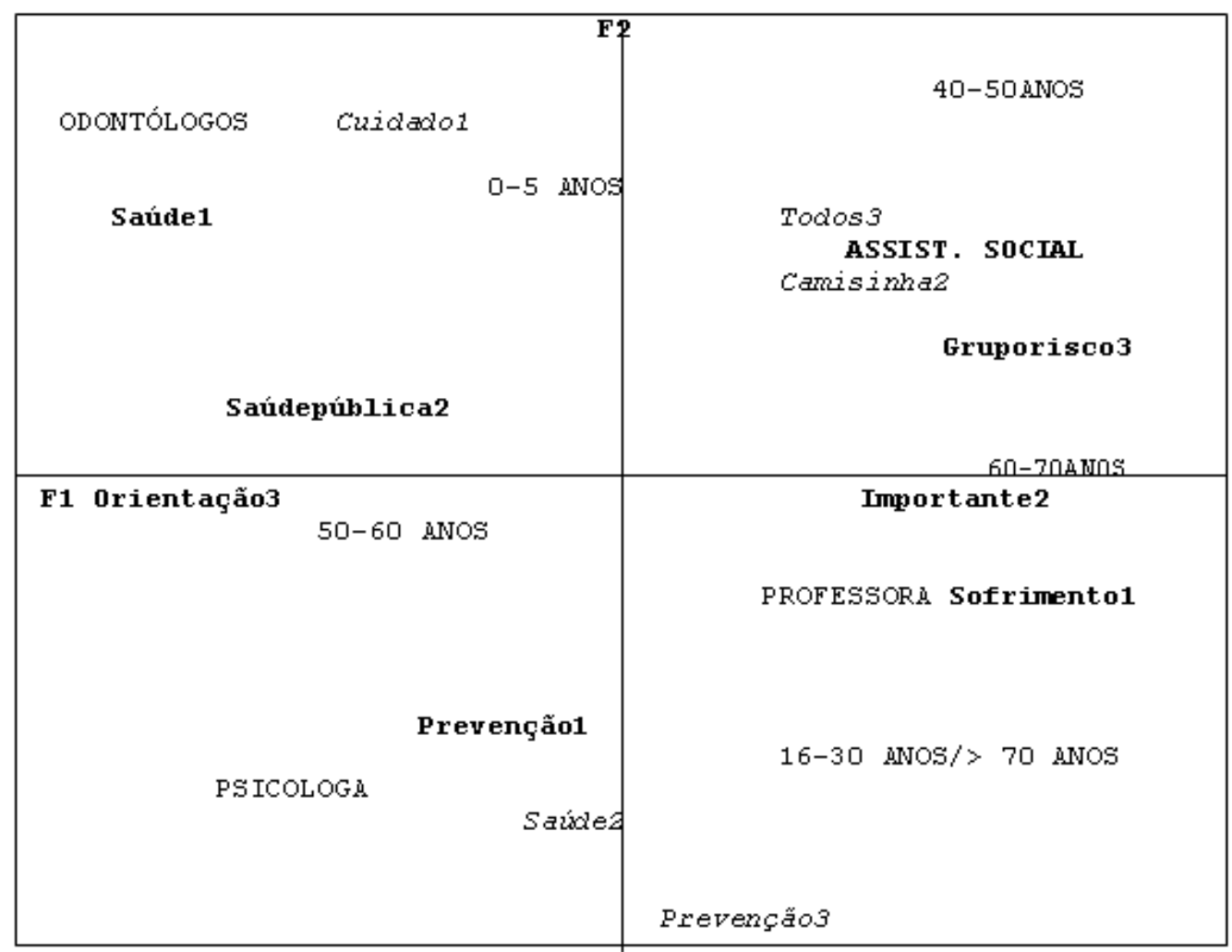

Figura 1 - Plano fatorial de correspondência das representações da Aids na terceira idade

A Figura 1 busca comparar as representações relativas à Aids na terceira idade, vulnerabilidade $\mathrm{e}$ prevenção, elaboradas pelas coordenadoras de grupo de terceira idade. A análise da figura realiza-se através da leitura das representações (palavras emergidas), interligadas a variáveis fixas que estão opostamente distribuídas.

No fator 1 (F1), representado pela linha horizontal, em negrito, no lado esquerdo, encontram-se as representações das coordenadoras com idade entre 50 e 60 anos, que mostram que a Aids na terceira idade é uma doença grave, que afeta a saúde dos idosos, e a questão da prevenção passa por uma responsabilidade da saúde pública e a vulnerabilidade está relacionada diretamente com a falta de orientação dos idosos sobre a Aids. No lado direito, verifica-se que as coordenadoras com idade entre 60-70 anos consideram a Aids uma doença que traz sofrimento na terceira idade, cuja prevenção é importante. A vulnerabilidade, segundo tais coordenadoras, está diretamente ligada aos grupos de risco.

No fator 2 (F2), representado pela linha vertical, em itálico, na parte superior, encontram-se as representações das coordenadoras com idade entre $40 e$ 50 anos. Este grupo entende que a Aids na velhice requer cuidado, atenção, estando a prevenção relacionada à camisinha; quanto à vulnerabilidade, refere-se a uma situação a que todos estão expostos. $\mathrm{Na}$ parte inferior encontram-se as coordenadoras com mais de 70 anos, que compreendem a Aids como uma questão que necessita de prevenção também na velhice, como proteção para a saúde, e a vulnerabilidade relacionada com uma questão de falta de cuidado, de falta de prevenção. Com relação ao fator tempo de trabalho, as profissões predominantes, em que o tempo de trabalho varia de 0 a 5 anos, são as de assistente social e odontóloga; já em relação ao tempo de trabalho, variando entre 16 e 30 anos, as profissões de psicóloga e de professora predominam.

Denota-se, mediante as representações elaboradas pelas participantes que trabalham com grupos de idosos há pelo menos 5 anos, que estas percebem a Aids no contexto da terceira idade como um problema de saúde grave, proveniente da falta de prevenção e causadora de sofrimento, enquanto as coordenadoras que trabalham com os grupos há mais de 16 anos ancoraram suas representações na questão relacionada ainda a grupos de risco, demonstrando, assim que as coordenadoras com mais tempo de trabalho nos grupos mantêm as representações iniciais da Aids.

As coordenadoras dos grupos com idades equivalentes a dos participantes dos grupos ancoraram 
suas representações do $\mathrm{HIV} /$ Aids em idosos em uma falta de responsabilidade dos próprios indivíduos, e quanto à prevenção, apresentam uma carência de conhecimentos acerca do assunto, limitando a contaminação aos grupos de riscos, estes que foram tão fortemente ratificados socialmente e que até os dias atuais são citados nos contextos mais diversos.

Os trabalhos desenvolvidos por Joffe (1998) descreveram como as representações da Aids têm uma relação entre alteridade e identidade; os resultados revelaram como a Aids tem sido ligada à responsabilidade e à culpabilidade de determinados grupos sociais entendidos como "outros". Essa forma de pensar a Aids faz com que um determinado grupo que se considere isento da infecção veja outros grupos como perigosos. Tais estudos corroboram os dados coletados com as coordenadoras dos grupos de idosos, principalmente aquelas de idade mais avançada, que, sendo idosas, também vêem como improvável a possibilidade do contágio com o vírus, quer seja por identificação com os grupos, quer seja por, historicamente, ancorar as representações da Aids no que a mídia anunciou fortemente ao longo de seu desenvolvimento.

Compreender como as coordenadoras ancoram suas representações acerca da Aids no contexto da terceira idade é fundamental para o desenvolvimento de práticas educativas no âmbito dos grupos de convivência. Mesmo com tantas dificuldades de ordem estrutural, as coordenadoras compreendem como a realidade do grupo - as reuniões, as dinâmicas - é essencial para práticas preventivas. Os grupos de convivência de idosos apresentam-se como espaços de transformação, onde, mediante a capacitação das coordenadoras acerca da Aids, os idosos poderão ser contemplados com intervenções preventivas, possibilitando-lhes a aquisição de estratégias de enfrentamento ao $\mathrm{HIV} /$ Aids.

\section{Considerações finais}

O presente estudo buscou, por meio da apreensão das representações das coordenadoras dos grupos de convivência acerca da Aids na velhice, verificar como este tema é compreendido por elas, e como essa compreensão auxilia ou interfere no trabalho com os idosos nos grupos em relação a essa temática.

A análise dos dados revelou como as coordenadoras ainda vêem como distante das realidades de seus grupos a vulnerabilidade dos idosos quanto ao HIV, principalmente ao longo dos relatos e dos preenchimentos dos instrumentos da pesquisa. Ficou claro como a compreensão dessa vulnerabilidade ainda está ancorada apenas nas relações tidas como "promíscuas", em que os idosos do sexo masculino não

Psico-USF, v. 13, n. 1, p. 95-103, jan./jun. 2008 se previnem e acabam, posteriormente, transmitindo o vírus a suas esposas.

Os grupos de convivência dos quais as participantes desta pesquisa são coordenadoras são constituídos primordialmente por idosas, fato que deve ser levado em consideração no desenvolvimento de práticas educativas de prevenção ao HIV; o processo de feminização da Aids, e também da velhice, corrobora ainda mais a necessidade de desenvolvimento de trabalhos que contemplem essa especificidade. Deve-se fugir da visão sexista, mas não se pode perder de vista a realidade dos grupos aqui citados. O desenvolvimento de trabalhos com as coordenadoras feitos anteriormente ao trabalho direto com os grupos pode promover de forma menos sexista o trabalho nos grupos, sem se deixar de contemplar as especificidades relativas a cada um deles.

A presença numericamente inferior dos homens nos grupos de convivência diante do grande número de mulheres pode ser justificada pelo viés cultural que entende a realidade desses grupos (os trabalhos e as atividades desenvolvidas) como sendo de natureza feminina, estereotipando os espaços e dificultando a permanência de idosos nesses grupos. O desenvolvimento de estudos posteriores pode revelar de forma mais precisa os reais motivos da pouca permanência dos idosos nesses espaços.

Esta pesquisa buscou contribuir para a compreensão das representações da Aids na velhice. O grupo participante da pesquisa pôde, através de seus relatos e dos dados coletados pelos instrumentos de pesquisa, fornecer importantes informações, que certamente auxiliaram no desenvolvimento mais qualificado de propostas de intervenções dentro do espaço privilegiado dos grupos de convivência de idosos. Além disso, essas informações também propiciam a todos os que trabalham com idosos uma visão mais realista da sexualidade vivida na velhice, favorecendo uma forma de pensar em que o atendimento e as intervenções nesse grupo etário ocorram de forma mais adequada, contemplando cada vez mais a qualidade de vida dos idosos, não apenas por pequenos grupos, mas também por todos inseridos na realidade social atual.

As coordenadoras e os grupos são primordiais para a disseminação de práticas preventivas do HIV/Aids, bem como de uma visão diferenciada da velhice e de suas formas de experenciar a sexualidade nessa fase da vida. Além das coordenadoras e de seus trabalhos, as políticas públicas voltadas ao atendimento aos idosos devem atentar para estas realidades apresentadas por diversas pesquisas como esta. Assim, provavelmente, incorrer-se-á cada vez menos na construção de políticas ineficazes que demonstram nada compreender sobre realidades às quais propõem intervenções. 
Sabe-se das limitações na presente pesquisa, porém, espera-se que ela possa auxiliar nas propostas de práticas cotidianas dos profissionais que trabalham nesses grupos e na compreensão da sexualidade - e, conseqüentemente, da Aids - na velhice, de forma menos estereotipada, em que as particularidades sejam contempladas, para que, assim, os tempos de ser velho sejam vividos com vigor e qualidade merecida em todas as etapas da vida.

\section{Referências}

Araujo, L. F., Coutinho, M. P. L. \& Carvalho, V. A. M. L. (2005). Representações sociais da velhice sobre a ótica de idosos que participam de grupos de convivência. Psicologia: Ciência e Profissão, 25 (1), p. 118 -131.

Araújo, L. F.; Coutinho; M. P. L. \& Santos, M. F. S. (2006). Análise psicossocial do idoso em instituições gerontológicas. Em D. V. S. Falcão \& C. M. S. B. Dias (Orgs.). Maturidade e velhice: pesquisas e intervençôes psicológicas (pp. 131-150). São Paulo: Casa do Psicólogo.

Bastos, F. I. (2001). A feminização da epidemia de Aids no Brasil: determinantes estruturais e alternativas de enfrentamento. Coleção ABIA: Saúde Sexual e Reprodutiva, 3. Rio de Janeiro: ABIA. Obtido em 20 de setembro de 2003 do World Wide Web: http://www.abiaids.org.br.

Borges, L. C. (2006). Os grupos de convivência na terceira idade: suporte social e afetivo. Em Falcão, D. V. S. \& Dias, C. M. S. B. Maturidade e velhice: pesquisa e intervencões psicológicas (pp. 131-150). São Paulo: Casa do Psicólogo.

Brasil, Ministério da Saúde (2000). Ativismo e liderança. Brasilia: CNDST/Aids.

Brasil, Ministério da Saúde (2005). Boletim epidemiológico Aids e DST. Brasilia: Ano II, n. 1, 1 $1^{\mathrm{a}}-26^{\mathrm{a}}$ semanas epidemiológicas, jan.-jun. de 2005.

Butin, N. G. (2002). Finitude e envelhecimento: significados da morte no idoso soropositivo. Tese de Mestrado. São Paulo: Pontifícia Universidade Católica de São Paulo Mestrado em Gerontologia.

Cabral, B. E. S. L. \& Oliveira, M. G. (2003). Lazer nos grupos de convivência para idosos: uma experiência de sociabilidade. Revista do Pós-graduandos de Sociologia da UFPb, 4. Obtido em 20 de outubro de 2006 do World Wide Web: http://www.cchla.ufpb.br/paraiwa/04guia_e_benedita.html.

Cavalcante, J. P. L. (2004). Envelhecimento e morte no mundo ocidental contemporâneo. Monografia de Especialização em Gerontologia. Universidade Federal da Paraíba - NIETI, João Pessoa-PB.
Cibois, Ph. (1998). L'analyse factorielle. Paris: PUF, Collecion "Que sais-je?".

Costa, F. G. \& Campos, P. H. F. (2003). Práticas institucionais e representações da exclusão na terceira idade. Em P. H. F. Campos \& M. C. S. Loureiro (Orgs.). Representação social e práticas educativas. Goiânia: Editora da UCG.

Coutinho, M. P. L. (2001). Depressão infantil: uma abordagem psicossocial. João Pessoa: Editora Universitária.

Cruz, G. E. C. P. (2005). HIV/Aids: um perfil epidemiológico de portadores idosos. Obtido em 16 de fevereiro de 2006 do World Wide Web: http://www.portaldoenvelhecimento.net/pforum/aid s1.htm.

Figueiredo, M. A. C. (2004). Um estudo de crenças e representações em cuidadores domésticos de pessoas com Aids e acompanhantes de ambulatório de crianças soropositivas para o HIV. Subsídios para programas de orientação e suporte psicológico do atendimento domiciliar. Ribeirão Preto-SP. Obtido em 21 de março de 2006 do World Wide Web: http:/ papsi.ffclrp.usp.br.

Gadelha. K. G. M. (2001). Curar-se das palavras: construcões discursivas dos portadores do HIV sobre a Aids. Centro de Humanidades. Dissertação de Mestrado em Sociologia. João Pessoa-PB: Universidade Federal da Paraíba.

Joffe, H. (1998). "Eu não, o meu grupo não": Representações Sociais transculturais da Aids. Em P. Guareschi \& S. Jovchelovitch (Orgs.). Textos em representações sociais (pp. 297-323). Petrópolis, RJ: Vozes.

Lima, M. P. (2006). Sexualidade "de terceira" na terceira idade? Psychologica: Sexualidades, 41, 83-102.

Lopes, C. R. (2005). A epidemia mudou e o mundo também. Radis 40 Comunicação em saúde. Rio de Janeiro: Fiocruz.

Marques, M. C. C. (2003). A história de uma epidemia moderna: a emergência política de Aids/HIV no Brasil. São Carlos: RIMA; Maringá: EDUEM.

Parker, R. \& Barbosa, R. M. (1996). Sexualidades brasileiras. Rio de Janeiro: Relume Dumará: ABIA: IMS/UERJ.

Reis, J. C.; Fradique, F. S. (2003). Significações sobre causas e prevenção das doenças em jovens adultos, adultos de meia-idade e idosos. Psicologia Teoria e Pesquisa, 19, (1), 224-242.

Saldanha, A. A. W. (2003). Vulnerabilidade e construcoues de enfrentamento da soropositividade ao HIV por mulheres infectadas em relacionamento estável. Tese de Doutorado. Ribeirão Preto, SP: Universidade de São Paulo - 
Faculdade de Filosofia, Ciências e Letras de Ribeirão Preto.

Saldanha, A. A. W., Araujo, L. F. \& Felix, S. M. F. (2006). Aids na velhice: os grupos de convivência de idosos como espaços de possibilidades. Em D. V. S. Falcão \& C. M. S. B. Dias. Maturidade e velhice: pesquisa e intervençôes psicológicas (pp. 126-233). São Paulo: Casa do Psicólogo.

Saldanha, A. A. W., Figueiredo, M. A. C. \& Coutinho, M. P. L. (2005). Aids: trajetória e tendência da epidemia - a legitimação de um universo simbólico. Em M. da P. de
L. A. A. W. Coutinho \& Saldanha. Representações sociais e práticas em pesquisa (pp. 153-172). João Pessoa: Editora Universitária/UFPB.

Sobre os autores:

Ana Alayde Werba Saldanha é doutora em Psicologia pela Universidade de São Paulo, Ribeirão Preto-SP; especialista em Saúde Coletiva, professora adjunta do Departamento de Psicologia e do Programa de PósGraduação em Psicologia Social da Universidade Federal da Paraíba e coordenadora do Projeto Vulnerabilidades e Construções de Enfrentamento à Aids.

Shenia Maria Felício Felix é graduanda em Psicologia, bolsista de Iniciação Científica (PIBIC/CNPq). pesquisadora do Núcleo de Pesquisa: Aspectos Psicossociais de Prevenção e Saúde Coletiva da Universidade Federal da Paraíba e integrante do projeto Vulnerabilidades e Construções de Enfrentamento à Aids.

Ludgleydson Fernandes Araújo é professor assistente do Departamento de Psicologia da Universidade Federal do Piauí - UFPI (Campus Ministro Reis Velloso - Parnaíba-PI), mestre em Psicologia Social, especialista em Gerontologia e pesquisador do Núcleo de Pesquisa: Aspectos Psicossociais de Prevenção e Saúde Coletiva da Universidade Federal da Paraíba. 
